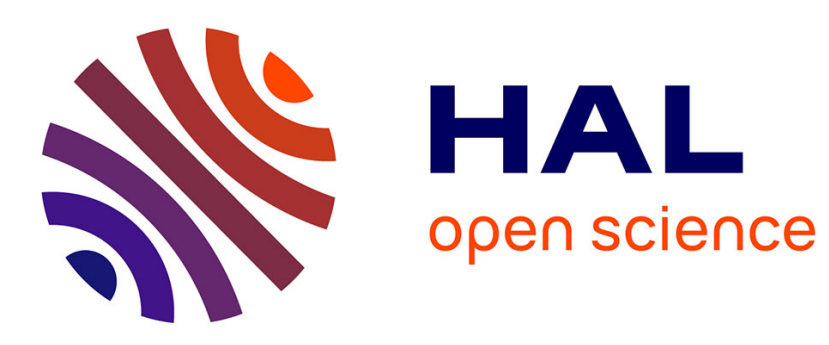

\title{
GAB1 overexpression identifies Hedgehog-activated anterior skull base meningiomas
}

Julien Boetto, Julie Lerond, Matthieu Peyre, Suzanne Tran, Pauline Marijon, Michel Kalamarides, Franck Bielle

\section{- To cite this version:}

Julien Boetto, Julie Lerond, Matthieu Peyre, Suzanne Tran, Pauline Marijon, et al.. GAB1 overexpression identifies Hedgehog-activated anterior skull base meningiomas. Neuropathology and Applied Neurobiology, 2021, 10.1111/nan.12740 . hal-03246116

\section{HAL Id: hal-03246116 https://hal.sorbonne-universite.fr/hal-03246116}

Submitted on 2 Jun 2021

HAL is a multi-disciplinary open access archive for the deposit and dissemination of scientific research documents, whether they are published or not. The documents may come from teaching and research institutions in France or abroad, or from public or private research centers.
L'archive ouverte pluridisciplinaire HAL, est destinée au dépôt et à la diffusion de documents scientifiques de niveau recherche, publiés ou non, émanant des établissements d'enseignement et de recherche français ou étrangers, des laboratoires publics ou privés. 
DR JULIEN BOETTO (Orcid ID : 0000-0003-2572-8594)

DR FRANCK BIELLE (Orcid ID : 0000-0001-6564-6388)

Article type : Original Article

\section{Title}

\section{GAB1 overexpression identifies Hedgehog-activated anterior skull base meningiomas}

\section{Authors}

Julien Boetto ${ }^{1,2}$, Julie Lerond ${ }^{2,3}$, Matthieu Peyre ${ }^{2,4,5}$, Suzanne $\operatorname{Tran}^{5,6}$, Pauline Marijon ${ }^{2,4}$, Michel Kalamarides ${ }^{2,4,5}$, Franck Bielle $2,3,6,7$

\section{Affiliations}

1 Department of Neurosurgery, Gui de Chauliac Hospital, Montpellier University Hospital Center, 80 Avenue Augustin Fliche, 34090 Montpellier, France.

2 CRICM INSERM U1127 CNRS UMR 7225, Institut du Cerveau et de la Moelle Epinière, Paris, F75013, France

\section{SiRIC CURAMUS (CANCER UNITED RESEARCH ASSOCIATING MEDICINE, UNIVERSITY}

\& SOCIETY) - site de recherche intégrée sur le cancer IUC - APHP.6 - Sorbonne Université, Paris, F75013, France.

4 Department of Neurosurgery, AP-HP, Hôpital Pitié-Salpêtrière, Paris, F-75013, France

5 Sorbonne Université, UPMC Univ Paris 06, Paris, F-75013, France

6 Department of Neuropathology, AP-HP, Hôpital Pitié Salpêtrière, Paris, F-75013, France

7 Onconeurotek, AP-HP, Hôpital Pitié-Salpêtrière, Paris, F-75013, France

This article has been accepted for publication and undergone full peer review but has not been through the copyediting, typesetting, pagination and proofreading process, which may lead to differences between this version and the Version of Record. Please cite this article as doi: 


\section{Corresponding author}

Franck Bielle

Department of Neuropathology

Hôpital de la Pitié Salpêtrière

47-83 Bd de l'Hôpital

75651 PARIS CEDEX 13, FRANCE

Phone : +33142161890

Fax : + 33142161899

franck.bielle@aphp.fr

KEYWORDS:

Meningioma; Skull base; Hedgehog; SMO; GAB1

SHORT RUNNING TITLE:

GAB1, surrogate marker of Hh-activated meningiomas

NUMBER OF WORDS:

NUMBER OF FIGURES: 4

NUMBER OF TABLES: 0

Supplementary figures: 5

Supplementary Tables: 3

This article is protected by copyright. All rights reserved 


\section{ABSTRACT}

AIMS:

Mutations activating the Hedgehog (Hh) signalling pathway have been described in anterior skull base meningiomas, raising hope for the use of targeted therapies. However, identification of Hh-activated tumours is hampered by the lack of a reliable immunohistochemical marker. We report the evaluation of GAB1, an immunohistochemical marker used to detect Hh pathway activation in medulloblastoma, as a potential marker of $\mathrm{Hh}$ activated meningiomas.

\section{METHODS:}

GAB1 staining was compared to SMO mutation detection with Sanger and NGS techniques as well as Hh pathway activation study through mRNA expression level analyses in a discovery set of 110 anterior skull base meningiomas and in a prospective validation set of 21 meningiomas.

\section{RESULTS:}

Using an expression score ranging from 0 to 400, we show that a cut-off score of 250 lead to excellent detection of $\mathrm{Hh}$ pathway mutations (sensitivity 100\%, specificity $86 \%$ ). The prospective validation set confirmed the excellent negative predictive value of GAB1 to exclude Hedgehog independent meningiomas. We describe a large series of 32 SMO-mutant meningiomas and define multiple ways of Hh activation, either through somatic mutations or associated with mutually co-exclusive SHH (Sonic Hedgehog) or IHH (Indian Hedgehog) overexpression independent of the mutations.

\section{CONCLUSION:}

The assessment of GAB1 expression by an immunohistochemical score is a fast and costefficient tool to screen anterior skull base meningiomas for activation of the Hedgehog 
pathway. It could facilitate the identification of selected cases amenable to sequencing for hedgehog pathway genes as predictive markers for targeted therapy.

\section{Conflicts of interest}

The authors disclose no conflict of interests with the content of the manuscript.

This article is protected by copyright. All rights reserved 


\section{INTRODUCTION}

Meningiomas are the most common primary central nervous system tumours in adults[1]. They are classified in three prognostic histological groups following the WHO classification: grade I (65 to $80 \%$, benign), grade II (20 to 35\%, atypical) and grade III (less than $3 \%$, anaplastic). Surgery remains the main treatment option for growing and/or symptomatic tumours. While most meningiomas are efficiently cured by surgery alone, there is a significant proportion of tumours that become surgery- and radiation-refractory over time without any other available treatment option in the absence of effective chemotherapy[2].

While loss of function of the NF2 suppressor gene is the well-established driver of at least $50 \%$ of meningiomas[3, 4], next generation sequencing (NGS) has led to the discovery of mutations in other oncogenes including AKT1, KLF4, SMO, PIK3CA, POLR2A and TRAF7, all being exclusive of $N F 2$ mutation [5-13]. These mutations define four main distinct meningioma molecular subgroups based on the mutational background: NF2/SMARCB1, TRAF7/KLF4, Pi3K-family genes/TRAF7 and Hedgehog pathway (Hh) [14, 15].

Uncontrolled activation of the Hedgehog $(\mathrm{Hh})$ pathway drives tumour progression in a number of cancers, including basal cell carcinoma and medulloblastoma[16]. Hedgehog pathway-activated (Hh-activated) meningiomas, which are theoretically targetable using the clinically approved SMO-inhibitor Vismodegib, when harbouring hotspot mutations in SMO, represent a highly heterogeneous subgroup. They comprise tumours with either $S M O, S U F U$ or PRKARIA mutations and represent $7.6 \%$ of all meningiomas $[5-11,17]$. The Hedgehog (Hh) signalling pathway plays an essential role during vertebrate embryonic development. The activation occurs by a ligand-dependent interaction when the Hedgehog proteins (Sonic, Desert and Indian Hedgehog) bind and inactivate the twelve-transmembrane protein Patched (PTCH1), releasing the activity of the seven-transmembrane protein, SMO. This downstream 
signalling cascade results in the dissociation of the Gli family proteins from their inhibiting factor SUFU, their translocation to the nucleus, and the transcription of target genes, including PTCHI and GLII[16]. Hh-activated meningiomas are enriched for meningothelial histology and mostly located at the median anterior skull base, suggesting a possible link between a molecular subgroup and an anatomical site of origin [7]. This association is supported by the embryonic activation of Hh signalling at the anterior skull base during the early development of murine meninges $[18,19]$. Moreover, our group showed a selective vulnerability of the primitive meningeal layer to prenatal Smo activation for skull base meningothelial meningioma formation in relevant mouse models[20].

DNA sequencing or molecular expression profiling alone cannot identify the subgroup of $\mathrm{Hh}$ activated meningiomas due to their heterogeneity. The discovery of a specific marker is therefore essential to identify these tumours in daily clinical practice and facilitate inclusion in clinical trials.

GAB1 immunohistochemistry is a surrogate marker of the SHH-activated genetic group of medulloblastoma in the WHO 2016 classification[1, 21] and had been described to be positive in the subgroup of $S M O$-mutant meningiomas[8]. Here, we study the link between GAB1 positivity and Hh pathway activation in meningiomas and show that GAB1 IHC is a powerful tool to identify Hh-activated meningiomas of the skull base in routine practice and to screen them before further targeted sequencing.

\section{Material and methods}

Patient and tissue samples. Collection of patient samples and clinicopathological information was undertaken with patient informed consent and Hospital ethical board approval. Patients with grade I meningioma arising from anterior skull base at initial diagnosis operated from 2003 to 2012 and fresh-frozen tumour sample available in the brain 
tumour bank (Onconeurotek, AP-HP, Paris) were selected for the retrospective cohort constitution (discovery set). Clinical data were reviewed and pathological diagnosis (subtype and grade according to WHO 2016 classification) was reviewed blind from further analyses (F.B.). The prospective cohort of patients (validation set) fulfilled the following criteria: $d e$ novo grade I anterior skull base meningioma at initial diagnosis operated from 2018 to 2020 and a fresh-frozen tumour sample available in the brain tumour bank.

Histochemistry and immunohistochemistry. Formalin-fixed paraffin-embedded tissue 3 micrometre-thick sections were deparaffinized. Periodic Acid Schiff, Alcian Blue, Reticulin and Masson's Trichrome stains were performed according to standard protocols. The sections were immunolabelled by a fully automated immunohistochemistry system, Ventana benchmark XT System (Roche, Basel, Switzerland), using a streptavidin-peroxidase complex with diaminobenzidine as the chromogen. Antigen retrieval for GAB1 was performed by heating at $\mathrm{pH}=8.4$ for $60 \mathrm{~min}$. The primary antibodies are shown in Supplementary Table 1. A positive control (Shh-activated medulloblastoma) was present in each run of GAB1 immunostaining. The GAB1 immunostaining was evaluated blind from genotype using an expression score ranging from 0 to 400 . The percentage of tumour cells at different staining intensities was determined by visual assessment independently by two pathologists (ST, FB). Score $=($ percentage of tumour area with very weak labelling x 1$)+($ percentage of tumour area with weak labelling $\mathrm{x} 2)+($ percentage of tumour area with moderate labelling $\mathrm{x} 3)+$ (percentage of tumour area with intense labelling $\mathrm{x} 4$ ). Linear regression was performed between the scores evaluated by the two pathologists.

This article is protected by copyright. All rights reserved 
Targeted sequencing. DNA was extracted from all fresh-frozen tumours using the QIAmp DNA minikit (Qiagen, Courtaboeuf, France) and quantified using Nanodrop (Thermo Fisher Scientific, Villebon sur Yvette, France). Mutational status of $S M O$ was determined for both cohorts by Sanger sequencing for L412F and W535L mutations. Details of PCR were as previously reported [7]. A subset of $S M O$-wildtype tumours was analysed by next generation sequencing for all known mutated genes in meningiomas using a custom assay developed at the Institut du Cerveau et de la Moelle Epinière (see [22] for full list of genes). DNA was quantified and quality-assessed using a NanoVue Plus spectrophotometer (GE Healthcare Life Sciences, Pittsburgh, MA). Target regions were captured from fragmented genomic DNA samples using a custom SeqCap EZ choice kit (Nimblegen), and paired-end 75-base massively parallel sequencing was carried out on an Illumina NextSeq500, according to the manufacturer's protocols.

RNA extraction and RT-qPCR. RNA was extracted from frozen tumour sample by RNA kit Maxwell (Promega) and quantified using Nanodrop (Thermo Fisher). RNA was retrotranscribed using the Maxima First Strand cDNA Synthesis Kit (Thermo Fischer). The cDNA obtained was used as a template for the determination of PTCH1, GLII, HHIP, IHH, SHH and DHH mRNA expression by qPCR on LightCycler® 96 (Roche, Bâle, Switzerland) using a Quantifast assay (Quiagen, Hilden, Germany). The $\Delta \mathrm{Ct}$ method was applied to normalise the mRNA levels using the expression of HPRT. The primer sets for qPCR were designed with the Roche Design Center (www.universalprobelibrary.com) and their sequence is shown in Supplementary Table 2. The level of expression is shown as a colour scale 1 or 2 standard deviations above or below the mean.

This article is protected by copyright. All rights reserved 
Statistical analysis. The Kruskal Wallis test was used to compare quantitative variable between more than two groups. The T test, and Mann and Whitney test with tie correction were used to compare quantitative variables by pairs and the $\mathrm{p}$ value was corrected for multiple comparisons. Distribution of categorical variables was compared with Fisher's exact test. All tests were two-sided and a p-value of $\leq 0.05$ was considered to be statistically significant. Statistical analyses were performed using Statview version 5.0 software (SAS institute, Cary, North Carolina, USA).

\section{RESULTS}

High GAB1 immunoreactivity is correlated with somatic mutations in the Hedgehog pathway.

A discovery set was constituted with 110 anterior skull base meningiomas, enriched for olfactory groove location, operated from 2003 to 2012. The main clinical and pathological characteristics of this set are summarized in Supplementary table 3. The flowchart (Supplementary Figure 1) summarizes the whole experiment.

We hypothesized that GAB1, an immunohistochemical surrogate marker of Hh activation in medulloblastoma, may detect Hh activation in the context of skull base meningioma. There was both inter- and intra-tumoural heterogeneity of GAB1 immunostaining and so, GAB1 expression was quantified using a quantitative score (range 0-400, Figure 1A-F). The linear regression of the independent evaluation by two pathologists showed a high correlation without significant systematic bias: $r^{2}=0.89$, slope of 1.007 and $y$-intercept of 7.4 corresponding to $3 \%$ of the threshold 250 (Supplemental Figure 2A). The Kappa coefficient for case above threshold of 250 was 0.91 , corresponding to an almost perfect agreement.

We next studied the correlation between GAB1 expression and SMO status from Sanger sequencing. Thirty-two lesions harbouring SMO mutations (31 L412F and $1 \mathrm{~W} 535 \mathrm{~L})$ were 
identified. GAB1 expression score was significantly higher in the SMO-mutants compared to the $S M O$-wildtype control group (Figure $1 \mathrm{G}-\mathrm{H}, \mathrm{p}<0,0001$ ). The score was equal or above 250 in all SMO-mutants, so we set the threshold of positivity (GAB1+) at 250 to obtain $100 \%$ sensitivity, and a score below 250 was considered GAB1 negative (GAB1-). In these settings, 46 meningiomas were GAB1+ (42\%), of which 32 cases were SMO-mutants and 14 cases were $S M O$-wildtype (Figure1G, see ROC curves in Supplemental Figure 2B and 2C).

Although the $14 \mathrm{GAB} 1+S M O$-wildtype cases appeared to be false positives, because Sanger sequencing failed to detect hotspot mutations of $S M O$, we reasoned that rarer mutations of the Hh pathway might be involved. We subjected those $14 \mathrm{GAB} 1+S M O$-wildtype tumours to NGS: four lesions had Hh-activating SMO or SUFU mutations (SMO L412F, SMO G416D, $S M O \mathrm{G} 529 \mathrm{~V}$, and $S U F U$ A340S, further called SMO-mutant for simplification). No PRKARIA mutation was found. Ten GAB1+SMO-wildtype tumours had no mutation of the Hh pathway by NGS (further called SMO-wildtype for simplification).

As a control cohort, we also subjected $13 \mathrm{GAB} 1$ - $S M O$-wildtype tumours randomly selected to NGS. We identified no Hh-activating mutations in GAB1- tumours, but as expected, found mutations in several alternative oncogenic pathways already reported in skull bases meningiomas (TRAF7, association of TRAF7 and KLF4, PIK3CA) (Figure 2A).

In summary, GAB1 showed a $100 \%$ sensitivity and an $86 \%$ specificity to detect mutations in the Hh pathway.

Identification of alternative Hh pathway activation in GAB1 highly immunopositive meningiomas.

We hypothesized that GAB1 positivity in these 10 tumours could be explained by the activation of the Hh pathway without somatic mutations in the Hh pathway. We thus performed Hh activation assays by studying the mRNA levels of GLII, PTCHI and HHIP, 
which are upregulated if the pathway is activated [16, 23]. As positive controls, we used meningiomas with mutations activating the Hh pathway, and as negative control, the GAB1tumours with no mutation $(\mathrm{n}=3)$ or TRAF7/PIK3CA mutations $(\mathrm{n}=8)$ (Figure $2 \mathrm{~A})$.

We observed significant overexpression of PTCHI ( $<<0,01)$, GLII $(\mathrm{p}<0,001)$ and HHIP $(\mathrm{p}<0,001)$ in $S M O$-mutant tumours $(\mathrm{n}=8 / 10)$ and in most GAB1+SMO-wildtype tumours $(n=8 / 10)$ compared to GAB1- tumours (Figure 2B and Supplementary Figure 3). These results suggest that GAB1 is a reliable marker of $\mathrm{Hh}$ pathway activation, independent of the mechanism of activation. Meningiomas with GAB1 negative staining harbouring alternative somatic mutations (TRAF7 or PIK3CA) showed low or absent activation of the Hh pathway (Supplementary Figure 3).

We next analysed the mRNA expression levels of canonical Hh ligands, Sonic Hedgehog (SHH), Desert Hedgehog (DHH) and Indian Hedgehog (IHH). SMO-mutant meningiomas showed activation of the Hh pathway without overexpression of $D H H, I H H$ and $S H H$, consistent with signalling activity independent of the ligands: only weak and non-significant level of $\mathrm{DHH}$ was detected (Supplementary Figure 3). Alternatively, we detected co-exclusive overexpression of IHH $(n=4)$ or SHH $(n=4)$ in GAB1+ SMO-wildtype tumours (Supplementary Figure 4).

Two SMO-wildtype Hh-activated (overexpressing GLI1, PTCH1, HHIP) tumours expressed neither $D H H$, nor $I H H$ nor $S H H$ suggesting that other unknown mechanisms caused $H$ h activation.

We computed a new ROC for the sensitivity and specificity of GAB1 IHC to detect Hh-activated meningiomas in the subgroup of tumours tested by RT-PCR. We assumed that all SMO-mutant tumours were Hh-activated. For a threshold of 250 (sensitivity=100\%), the specificity was $83 \%$ when a true positive is a Hh-activated status (Supplementary Figure 1B). 


\section{Prospective validation set study shows good ability of GAB1 to screen for $S M O$-mutant meningiomas in daily practice.}

In order to validate GAB1 as a screening marker for Hh-activated meningiomas, 21 anterior skull base meningiomas were prospectively screened by GAB1 immunostaining and $S M O$ Sanger sequencing from 2018 to 2020. 12 tumours were GAB1+ (score from 250 to 330, median score 290): 6 meningiomas out of the GAB1+ (50\%) harboured a SMO mutation (5 with $\mathrm{L} 412 \mathrm{~F}$ and 1 with W535L). All SMO-mutant had GAB1 positive staining. The diagnostic characteristics compared to SMO Sanger sequencing were: sensitivity $100 \%$, specificity $60 \%$, positive predictive value $50 \%$, negative predictive value $100 \%$.

\section{Recurrent histopathological features in SMO- mutant meningiomas.}

We investigated if $S M O$-mutant meningiomas and $\mathrm{Hh}$-activated meningiomas were associated with specific clinical or histological features. As previously described, SMO-mutant meningiomas are strongly biased towards the anterior skull base location, and more specifically towards an olfactory location (Supplementary Table 3). All were grade I meningothelial lesions. We found a significant association between an original histological feature and SMO-mutant meningiomas $\left(\mathrm{p}<4 \times 10^{-7}\right)$ : tumour cells bordered hollow pseudoglandular clefts and showed polarization of their nuclei towards the cleft (Figure 3A-C). This finding does not correspond to a WHO 2016 histological variant of meningioma. The clefts were elongated and did not contain eosinophilic material by contrast with the round lumens containing an eosinophilic material observed in secretory meningioma. The tumour cells did not form hepatoid rows observed in chordoid meningiomas. Moreover, histochemical stains did not detect a collagenous or a polysaccharide extracellular matrix in the clefts (Supplementary Figure 5). CD34 immunostaining was negative showing that these lumens do 
not correspond to blood vessels. The clefts often contained a CD3+ T lymphocyte or a CD163+ macrophage.

\section{DISCUSSION}

The activation of the Hedgehog pathway (Hh) through SMO mutations has been previously reported for anterior skull base meningiomas and, especially, olfactory groove grade I meningiomas[7, 9]. SMO mutations tend to have adverse prognostic value for tumour recurrence $[7,24]$. The identification of these mutations paved the way for a targeted therapeutic intervention for tumours relapsing after conventional care (surgery and radiation therapy). However, the identification of Hh-activated meningiomas is hindered by the heterogeneity of causal mechanisms. Variable mutations in SMO, SUFU and PRKARIA were described, and Hedgehog pathway activation was also highlighted independently from somatic mutation within the pathway [25].

Here, we show that GAB1 immunostaining is a powerful tool to identify Hh-activated skull base meningiomas, irrespective of the underlying mechanism of Hh activation. GAB1 was previously selected from transcriptomic data to be a surrogate marker of Shh-activated medulloblastomas [21]. GAB1 immunostaining has been validated and is now routinely used worldwide for the genetic diagnosis of medulloblastomas. We hypothesized that this easily available tool could be transferred to Hh-activated meningiomas. In medulloblastomas, GAB1 works as a binary result, that is the presence or absence of immunostaining of tumour cells. By contrast, we observed a wide spectrum of GAB1 immunostaining (from focal and weak to strong and diffuse) in skull base meningiomas. We therefore developed a quantitative GAB1 IHC score (range 0-400) based on visual evaluation by the pathologist of the intensity of staining and the ratio of immunolabelled tumour surface. This method is derived from the previously described EGFR expression score in lung carcinomas[26]. GAB1+ meningiomas 
harboured somatic activation mutations in Hh pathway in $78 \%$ of cases $(36 / 46)$, and an activation of the Hh pathway (assessed by transcriptomic mRNA levels and/or somatic mutations) in $95 \%$ of cases $(44 / 46)$.

Interestingly, this $\mathrm{Hh}$ activation was associated with a different profile of mRNA expression of the Hh ligands $(S H H, I H H$ or $D H H)$ depending on the causal mechanism. Cases with $\mathrm{Hh}$ activation without somatic activating mutations showed mutually exclusive $I H H$ or $S H H$ expression, or even neither $I H H, D H H$ nor $S H H$ expression in two cases. Our results suggest that ligand-independent autocrine or paracrine mechanisms could be involved in $\mathrm{Hh}$ activation in some SMO/SUFU wildtype tumours. They confirmed the diversity of mechanisms of activation of the Hh pathway in meningiomas that remain to be understood and showed the ability of GAB1 IHC to detect them all.

The presence of pseudoglandular clefts in $S M O / S U F U$ mutant meningiomas represents a new histological feature of meningiomas, not described in the WHO classification of CNS tumours, although the cellular mechanisms shaping this architecture remain to be elucidated. While this histological pattern is not constant and cannot replace the GAB1 IHC score, it may be useful to draw the attention of the pathologist to the possibility of Hh-activation and suggest that they investigate the genotype in search of SMO/SUFU mutations.

The prevalence of Hh activation varied greatly between olfactory and other skull base meningiomas. In our cohort, $37 \%$ of olfactory meningiomas are SMO/SUFU mutant and $42 \%$ are Hh-activated. This percentage decreases as more posterior lesions are explored, with a clear descending antero-posterior gradient, as previously described for the prevalence of $S M O$ mutations. These data may inform the feasibility of future clinical trials, as the NCT02523014 trial, a phase 2 trial studying the effect of Vismodegib on SMO-mutant meningiomas, faced difficulties in recruiting patients, and is by now suspended. Due to the relative rarity of SMO mutations, routine markers are thus needed to facilitate their screening. We suggest that 
GAB1 staining should be routinely performed for anterior skull base meningiomas (defined as arising anteriorly to the sphenoidal ridge), and that it could be a useful marker to facilitate the identification of $S M O$-mutant lesions. Its excellent negative predictive value enables one to exclude Hh-pathway activation (and Hh-pathway mutations) in GAB1 negative cases. In case of GAB1 positivity, further molecular analysis and sequencing would be necessary to identify the precise mechanism (SMO, SUFU, PRKARIA, other or no mutation). This strategy would undoubtedly facilitate the identification of meningiomas with SHH pathway activation amenable to targeted therapy with SMO-inhibitors (Figure 4). However, the GAB1 score and threshold have still to be validated in other centres, since all samples of this study come from a single institution. We advise the systematic use of SHH-activated medulloblastomas as a positive control for the immunostaining protocol, when using GAB1 IHC for meningiomas. As for other biomarkers, the reproducibility of the result also depends on the quality of the tissue. Pathologists have to manage pre-analytical parameters (including cold ischaemia, fixation, embedding and section thickness) and to exclude low quality or exiguous samples. Local validation through Sanger sequencing of some samples with different GAB1 scores may also be useful to validate the optimal threshold inherent to local protocols.

It is not perfectly established which patients will benefit from targeted therapies with SMO inhibitors. Studies in medulloblastoma demonstrated that SHH medulloblastomas with mutations downstream of SMO (e.g., SUFU, GLI2 or $M Y C N$ ) show primary resistance to targeted SMO inhibition with LDE-225 [27]. These results suggest that SMO inhibitors should target SMO-mutant meningiomas, but not Hedgehog activation downstream of SMO. Other pathway inhibitors, such as GLI-inhibitors, could become promising future tools for treatment of $\mathrm{Hh}$ activated meningiomas without $S M O$ mutations [16].

Molecular markers such as mutations reclassify common histological tumour types into rare diseases. This rarity challenges the management of molecularly-stratified clinical 
trials. We advocate uniting substantial numbers of skull base meningiomas into a group of tumours with the same oncogenic signalling thanks to GAB1 immunostaining, which will, we hope, facilitate a future clinical trial.

\section{Acknowledgements}

We are grateful to the technical staff of the Department of Neuropathology for immunostaining. We thank Yannick Marie and the IgenSeq platform for NGS.

Author's contribution: Study design: JB, MP, MK, FB. Data collection: JB, PM, ST. Pathological review: ST, FB. Experiments: JB, JL. Data analysis: JB, JL, FB. Manuscript drafting: JB, MP, MK, FB. Supervision of the study: MK, FB.

\section{Ethical approval}

Collection of patients samples and clinico-pathological information was undertaken with patient informed consent and hospital ethical board approval.

\section{Funding}

FB's work is funded by Fondation ARC pour la recherche sur le cancer (PJA 20151203562) and Emergence Sorbonne Universités 2019. SiRIC CURAMUS is financially supported by the French National Cancer Institute, the French Ministry of Solidarity and Health and Inserm INCA-DGOS-Inserm_12560. JL is funded by SIRIC CURAMUS. JB is funded by the "Poste Accueil" from the INSERM, has previous funding by a grant from UM1 University, Montpellier, France. This work was also supported by a grant from the Fondation ARC (PJA 20131200431). ST is funded by Association pour la Recherche sur les Tumeurs Cérébrales. 


\section{Conflicts of interest}

The authors disclose no conflict of interests with the content of the manuscript.

\section{Data Availability Statement}

Data available on request from the authors.

\section{References}

1 Louis DN, Ohgaki H, Wiestler OD, Cavenee WK. WHO classification of tumours of the central nervous system, Revised. 4th update ed. Lyon: International Agency for Research On Cancer. 2016

2 Rogers L, Barani I, Chamberlain M, Kaley TJ, McDermott M, Raizer J, Schiff D, Weber DC, Wen PY, Vogelbaum MA. Meningiomas: knowledge base, treatment outcomes, and uncertainties. A RANO review. J Neurosurg 2015; 122: 4-23

3 Kros J, de Greve K, van Tilborg A, Hop W, Pieterman H, Avezaat C, Lekanne Dit Deprez R, Zwarthoff E. NF2 status of meningiomas is associated with tumour localization and histology. J Pathol 2001; 194: 367-72

4 Ruttledge MH, Sarrazin J, Rangaratnam S, Phelan CM, Twist E, Merel P, Delattre O, Thomas G, Nordenskjold M, Collins VP, et al. Evidence for the complete inactivation of the NF2 gene in the majority of sporadic meningiomas. Nat Genet 1994; 6: 180-4

5 Abedalthagafi M, Bi WL, Aizer AA, Merrill PH, Brewster R, Agarwalla PK, Listewnik ML, Dias-Santagata D, Thorner AR, Van Hummelen P, Brastianos PK, Reardon DA, Wen PY, Al-Mefty O, Ramkissoon SH, Folkerth RD, Ligon KL, Ligon AH, Alexander BM, Dunn IF, Beroukhim R, Santagata S. Oncogenic PI3K mutations are as common as AKT1 and SMO mutations in meningioma. Neuro Oncol 2016; 18: 649-55

6 Bi WL, Abedalthagafi M, Horowitz P, Agarwalla PK, Mei Y, Aizer AA, Brewster R, Dunn GP, Al-Mefty O, Alexander BM, Santagata S, Beroukhim R, Dunn IF. Genomic landscape of intracranial meningiomas. J Neurosurg 2016; 125: 525-35

7 Boetto J, Bielle F, Sanson M, Peyre M, Kalamarides M. SMO mutation status defines a distinct and frequent molecular subgroup in olfactory groove meningiomas. Neuro Oncol 2017; 19: 345-51

8 Brastianos PK, Horowitz PM, Santagata S, Jones RT, McKenna A, Getz G, Ligon KL, Palescandolo E, Van Hummelen P, Ducar MD, Raza A, Sunkavalli A, Macconaill LE, Stemmer-Rachamimov AO, Louis DN, Hahn WC, Dunn IF, Beroukhim R. Genomic sequencing of meningiomas identifies oncogenic SMO and AKT1 mutations. Nat Genet 2013; 45: 285-9

9 Clark VE, Erson-Omay EZ, Serin A, Yin J, Cotney J, Ozduman K, Avsar T, Li J, Murray PB, Henegariu O, Yilmaz S, Gunel JM, Carrion-Grant G, Yilmaz B, Grady C,

This article is protected by copyright. All rights reserved 
Tanrikulu B, Bakircioglu M, Kaymakcalan H, Caglayan AO, Sencar L, Ceyhun E, Atik AF, Bayri Y, Bai H, Kolb LE, Hebert RM, Omay SB, Mishra-Gorur K, Choi M, Overton JD, Holland EC, Mane S, State MW, Bilguvar K, Baehring JM, Gutin PH, Piepmeier JM, Vortmeyer A, Brennan CW, Pamir MN, Kilic T, Lifton RP, Noonan JP, Yasuno K, Gunel M. Genomic analysis of non-NF2 meningiomas reveals mutations in TRAF7, KLF4, AKT1, and SMO. Science 2013; 339: 1077-80

10 Clark VE, Harmanci AS, Bai H, Youngblood MW, Lee TI, Baranoski JF, ErcanSencicek AG, Abraham BJ, Weintraub AS, Hnisz D, Simon M, Krischek B, ErsonOmay EZ, Henegariu O, Carrion-Grant G, Mishra-Gorur K, Duran D, Goldmann JE, Schramm J, Goldbrunner R, Piepmeier JM, Vortmeyer AO, Gunel JM, Bilguvar K, Yasuno K, Young RA, Gunel M. Recurrent somatic mutations in POLR2A define a distinct subset of meningiomas. Nat Genet 2016; 48: 1253-9

11 Domingues P, Gonzalez-Tablas M, Otero A, Pascual D, Ruiz L, Miranda D, Sousa P, Goncalves JM, Lopes MC, Orfao A, Tabernero MD. Genetic/molecular alterations of meningiomas and the signaling pathways targeted. Oncotarget 2015; 6: 10671-88

12 Strickland MR, Gill CM, Nayyar N, D'Andrea MR, Thiede C, Juratli TA, Schackert G, Borger DR, Santagata S, Frosch MP, Cahill DP, Brastianos PK, Barker FG, 2nd. Targeted sequencing of SMO and AKT1 in anterior skull base meningiomas. $\mathbf{J}$ Neurosurg 2017; 127: 438-44

13 Clark VE, Harmanc1 AS, Bai H, Youngblood MW, Lee TI, Baranoski JF, ErcanSencicek AG, Abraham BJ, Weintraub AS, Hnisz D, Simon M, Krischek B, ErsonOmay EZ, Henegariu O, Carrión-Grant G, Mishra-Gorur K, Durán D, Goldmann JE, Schramm J, Goldbrunner R, Piepmeier JM, Vortmeyer AO, Günel JM, Bilgüvar K, Yasuno K, Young RA, Günel M. Recurrent somatic mutations in POLR2A define a distinct subset of meningiomas. Nat Genet 2016; 48: 1253-9

14 Youngblood MW, Duran D, Montejo JD, Li C, Omay SB, Ozduman K, Sheth AH, Zhao AY, Tyrtova E, Miyagishima DF, Fomchenko EI, Hong CS, Clark VE, Riche M, Peyre M, Boetto J, Sohrabi S, Koljaka S, Baranoski JF, Knight J, Zhu H, Pamir MN, Avsar T, Kilic T, Schramm J, Timmer M, Goldbrunner R, Gong Y, Bayri Y, Amankulor N, Hamilton RL, Bilguvar K, Tikhonova I, Tomak PR, Huttner A, Simon M, Krischek B, Kalamarides M, Erson-Omay EZ, Moliterno J, Gunel M. Correlations between genomic subgroup and clinical features in a cohort of more than 3000 meningiomas. J Neurosurg 2019: 1-10

15 Harmanci AS, Youngblood MW, Clark VE, Coskun S, Henegariu O, Duran D, ErsonOmay EZ, Kaulen LD, Lee TI, Abraham BJ, Simon M, Krischek B, Timmer M, Goldbrunner R, Omay SB, Baranoski J, Baran B, Carrion-Grant G, Bai H, MishraGorur K, Schramm J, Moliterno J, Vortmeyer AO, Bilguvar K, Yasuno K, Young RA, Gunel M. Integrated genomic analyses of de novo pathways underlying atypical meningiomas. Nat Commun 2017; 8: 14433

16 Gonnissen A, Isebaert S, Haustermans K. Targeting the Hedgehog signaling pathway in cancer: beyond Smoothened. Oncotarget 2015; 6: 13899-913

17 Aavikko M, Li SP, Saarinen S, Alhopuro P, Kaasinen E, Morgunova E, Li Y, Vesanen K, Smith MJ, Evans DG, Poyhonen M, Kiuru A, Auvinen A, Aaltonen LA, Taipale J, Vahteristo P. Loss of SUFU function in familial multiple meningioma. Am J Hum Genet 2012; 91: 520-6

18 Wu SC, Grindley J, Winnier GE, Hargett L, Hogan BL. Mouse Mesenchyme forkhead 2 (Mf2): expression, DNA binding and induction by sonic hedgehog during somitogenesis. Mech Dev 1998; 70: 3-13

This article is protected by copyright. All rights reserved 
19 Xavier GM, Seppala M, Barrell W, Birjandi AA, Geoghegan F, Cobourne MT. Hedgehog receptor function during craniofacial development. Dev Biol 2016; 415: 198215

20 Boetto J, Apra C, Bielle F, Peyre M, Kalamarides M. Selective vulnerability of the primitive meningeal layer to prenatal Smo activation for skull base meningothelial meningioma formation. Oncogene 2018; 37: 4955-63

21 Ellison DW, Dalton J, Kocak M, Nicholson SL, Fraga C, Neale G, Kenney AM, Brat DJ, Perry A, Yong WH, Taylor RE, Bailey S, Clifford SC, Gilbertson RJ. Medulloblastoma: clinicopathological correlates of SHH, WNT, and non-SHH/WNT molecular subgroups. Acta Neuropathol 2011; 121:381-96

22 Peyre M, Gaillard S, de Marcellus C, Giry M, Bielle F, Villa C, Boch AL, Loiseau H, Baussart B, Cazabat L, Raffin-Sanson ML, Sanson M, Kalamarides M. Progestinassociated shift of meningioma mutational landscape. Ann Oncol 2018; 29: 681-6

23 Katoh Y, Katoh M. Hedgehog signaling pathway and gastrointestinal stem cell signaling network (review). Int J Mol Med 2006; 18: 1019-23

24 Youngblood MW, Miyagishima DF, Jin L, Gupte T, Li C, Duran D, Montejo JD, Zhao A, Sheth A, Tyrtova E, Özduman K, Iacoangeli F, Peyre M, Boetto J, Pease M, Avşar T, Huttner A, Bilguvar K, Kilic T, Pamir MN, Amankulor N, Kalamarides M, ErsonOmay EZ, Günel M, Moliterno J. Associations of Meningioma Molecular Subgroup and Tumor Recurrence. Neuro Oncol 2020:

25 Prager BC, Vasudevan HN, Dixit D, Bernatchez JA, Wu Q, Wallace LC, Bhargava S, Lee D, King BH, Morton AR, Gimple RC, Pekmezci M, Zhu Z, Siqueira-Neto JL, Wang X, Xie Q, Chen C, Barnett GH, Vogelbaum MA, Mack SC, Chavez L, Perry A, Raleigh DR, Rich JN. The Meningioma Enhancer Landscape Delineates Novel Subgroups and Drives Druggable Dependencies. Cancer Discov 2020; 10: 1722-41

26 Hirsch FR, Varella-Garcia M, Bunn PA, Jr., Di Maria MV, Veve R, Bremmes RM, Baron AE, Zeng C, Franklin WA. Epidermal growth factor receptor in non-small-cell lung carcinomas: correlation between gene copy number and protein expression and impact on prognosis. J Clin Oncol 2003; 21: 3798-807

27 Kool M, Jones DT, Jäger N, Northcott PA, Pugh TJ, Hovestadt V, Piro RM, Esparza LA, Markant SL, Remke M, Milde T, Bourdeaut F, Ryzhova M, Sturm D, Pfaff E, Stark S, Hutter S, Seker-Cin H, Johann P, Bender S, Schmidt C, Rausch T, Shih D, Reimand J, Sieber L, Wittmann A, Linke L, Witt H, Weber UD, Zapatka M, König R, Beroukhim R, Bergthold G, van Sluis P, Volckmann R, Koster J, Versteeg R, Schmidt S, Wolf S, Lawerenz C, Bartholomae CC, von Kalle C, Unterberg A, Herold-Mende C, Hofer S, Kulozik AE, von Deimling A, Scheurlen W, Felsberg J, Reifenberger G, Hasselblatt M, Crawford JR, Grant GA, Jabado N, Perry A, Cowdrey C, Croul S, Zadeh G, Korbel JO, Doz F, Delattre O, Bader GD, McCabe MG, Collins VP, Kieran MW, Cho YJ, Pomeroy SL, Witt O, Brors B, Taylor MD, Schüller U, Korshunov A, Eils R, Wechsler-Reya RJ, Lichter P, Pfister SM. Genome sequencing of SHH medulloblastoma predicts genotyperelated response to smoothened inhibition. Cancer Cell 2014; 25: 393-405 


\section{Figure Legends}

\section{Figure 1. Quantification of GAB1 immunolabeling.}

A. Very weak intensity GAB1 immunolabelling corresponding to coefficient 1. B. Weak intensity GAB1 immunolabelling corresponding to coefficient 2. C. Moderate intensity GAB1 immunolabelling corresponding to coefficient 3. D. High intensity GAB1 immunolabelling corresponding to coefficient 4 . E. A case with an IHC GAB1 score of 180 , equal to $30 * 1+$ $60 * 2+10 * 3+0 * 4(20 \%$ of surface with very weak intensity (coefficient 1$), 60 \%$ of surface with weak intensity (coefficient 2), $20 \%$ of surface with moderate intensity (coefficient 3), 0\% with high intensity (coefficient 4). F. A case with an IHC GAB1 score of 350 , equal to $0 * 1+10 * 2+30 * 3+60 * 4$. G. IHC GAB1 scores of skull base meningiomas defined as $S M O$ wildtype (blue), or $S M O$ mutant (red) according to Sanger sequencing. H. Whisker plots (median, IQR, range) showing same data as $\mathrm{G}$. $\mathrm{p}<0,0001$ ( $\mathrm{t}$ test).

Scale bars: A-D, 50 micrometres. E-F 500 micrometres

\section{Figure 2. Case-by-case analysis of GAB1 score, genotype and Hh pathway activation}

A. The immunohistochemical GAB1 expression score (positive if $>250$ ) is shown according to genotype and mRNA expression of members of the Hedgehog pathway. The relative mRNA level of expression of $D H H, I H H, S H H, G L I 1, H H I P, P T C H 1$ measured by RT-PCR is shown for each sample. Mutations are represented in the table.

B. mRNA expression of PTCH1, GLII, and HHIP in three subgroups of meningiomas, showing overexpression of Hh pathway markers in SMO-mutant and GAB1+SMO-wildtype lesions compared to GAB1- lesions. ${ }^{* *} \mathrm{p}<0,01 * * * \mathrm{p}<0,001$ (Mann Whitney) 


\section{Figure 3. Histopathological features of $S M O / S U F U$ mutant meningiomas}

A. Haematoxylin and eosin staining (H\&E) at low magnification showing frequent pseudoglandular clefts in a SMO-mutant meningioma. B. H\&E at high magnification showing hollow pseudoglandular clefts bordered by arachnoidal tumour cells. The nuclei of the tumour cells are polarized towards the clefts. C. Frequent pseudoglandular clefts were observed in 12/36 SMO/SUFU-mutant meningiomas and in none of 74 meningiomas of other molecular groups $\left(\mathrm{p}<4 \times 10^{-7}\right.$ Fisher test).

Scale bars: A, 100 micrometres. B 25 micrometres

\section{Figure 4. Proposed use of GAB1 in the detection of $\mathrm{Hh}$ activated meningiomas}

GAB1 staining may be routinely performed for anterior skull base meningiomas (defined as arising anteriorly to the sphenoidal ridge). Its excellent negative predictive value enables the exclusion of Hh-pathway activation (and Hh-pathway mutations) in GAB1 negative cases. In case of GAB1 positivity, further molecular analysis and sequencing would be necessary to identify the precise mechanism (SMO, SUFU, PRKARIA, other or no mutation) to adapt potential targeted treatment.

This article is protected by copyright. All rights reserved 


\section{Supplementary Figure Legends}

Supplementary Figure 1. Flow chart of the study with sequential experiments conducted.

\section{Supplementary Figure 2. ROC curves of GAB IHC expression score.}

A. Linear regression comparing the GAB1 score evaluated independently by two pathologists. The slope was close to 1 with no significant systematic bias: the y-intercept was 7.4 corresponding to $3 \%$ of the score 250 (threshold).

B. The extrapolated true positive rate of GAB1 IHC is depicted according to its false positive rate in the whole GAB1 IHC cohort $(n=110)$ : the gold standard for GAB1 IHC positivity is SMO-mutant status by Sanger sequencing (blue curve), SMO/SUFU mutant status as determined by NGS (green curve), or Hh-activated status as determined by RT-PCR (red curve). The extrapolation assumed that GAB1- tumours that are not tested by NGS are SMO/SUFU wildtype and Hh-inactive.

C. The true positive rate of GAB1 IHC is depicted according to its false positive rate in the subgroup of tumours analysed by NGS and RT-PCR ( $n=27)$ : the gold standard for GAB1 IHC positivity is $S M O$-mutant status by Sanger sequencing (blue curve), SMO/SUFU mutant status as determined by NGS (green curve), or Hh-activated status as determined by RT-PCR (red curve). The threshold of GAB1 score equal or superior to 250 corresponded to the lowest false positive rate for a $100 \%$ sensitivity in $\mathrm{A}$ and $\mathrm{B}$.

\section{Supplementary Figure 3. mRNA expression of the Hh pathway markers by sample} mRNA expression of PTCH1, GLI1, HHIP, IHH, SHH and DHH for each sample. $I H H$ was overexpressed in 3 tumours of the "GAB1+ No Mutation" group but there was no significant 
difference between the mean IHH expression of the 8 tumours of the "GAB1+ No Mutation" and the other groups.

Supplementary Figure 4. mRNA expression of the Hh pathway ligands by subgroups mRNA expression of $I H H, S H H, D H H$ in the three subgroups of meningiomas. ${ }^{*} \mathrm{p}<0,05$ $* * \mathrm{p}<0,01 * * * \mathrm{p}<0,001$ (Mann Whitney)

\section{Supplementary Figure 5. Histochemical and immunohistochemical characterization of} pseudoglandular clefts in $S M O / S U F U$ mutant meningiomas

Haematoxylin and eosin staining showing pseudoglandular clefts (A). Tumour cells bordered pseudoglandular clefts without vessels (CD34 immunolabelling, B) but with T lymphocytes (CD3 immunolabelling, arrow in C) and macrophages (CD163 immunolabelling, arrow in D). Periodic acid Schiff $(E)$, Alcian blue $(F)$, reticulin stain $(\mathrm{G})$ and Masson's trichrome $(\mathrm{H})$ did not stain extracellular matrix inside the clefts.

This article is protected by copyright. All rights reserved 


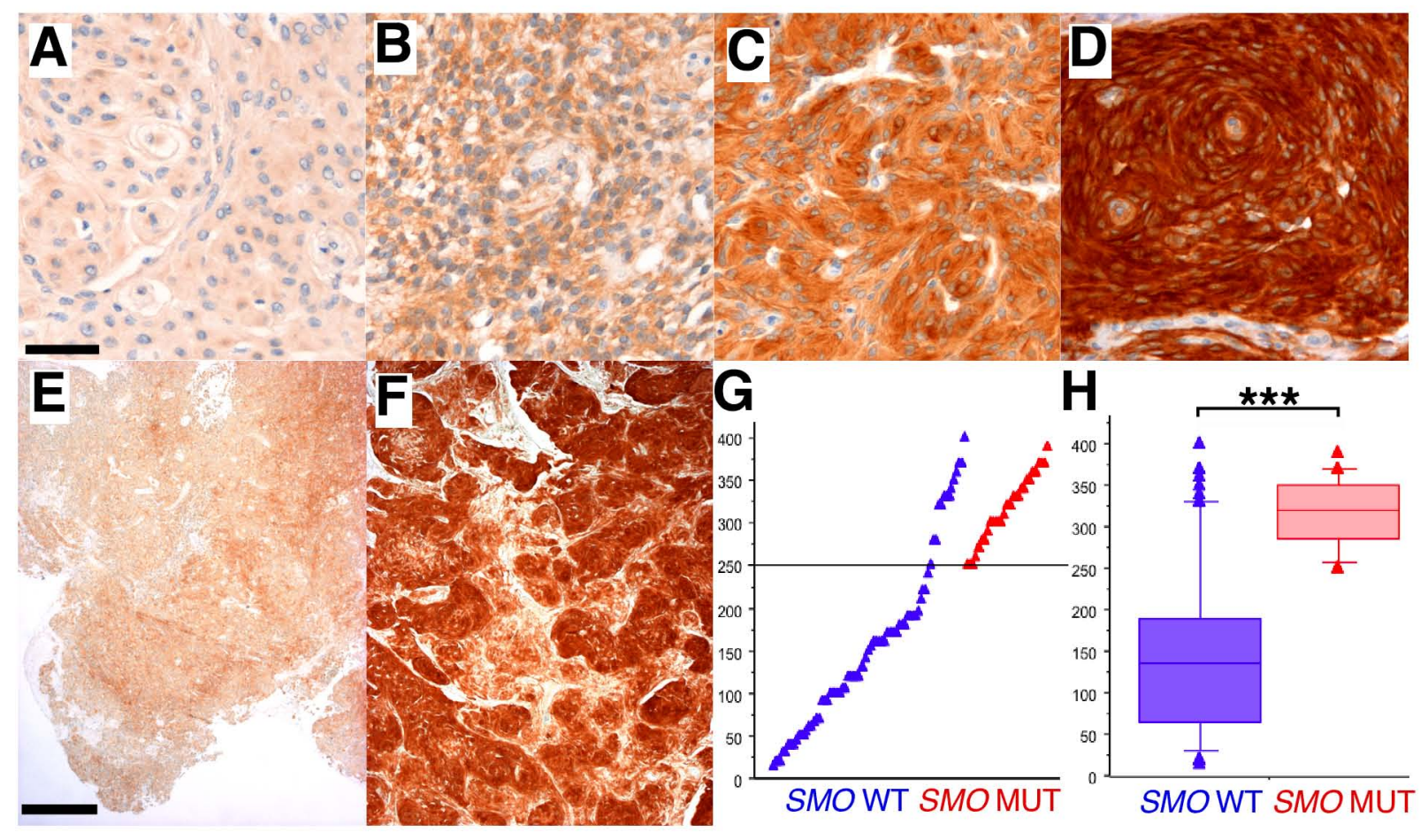



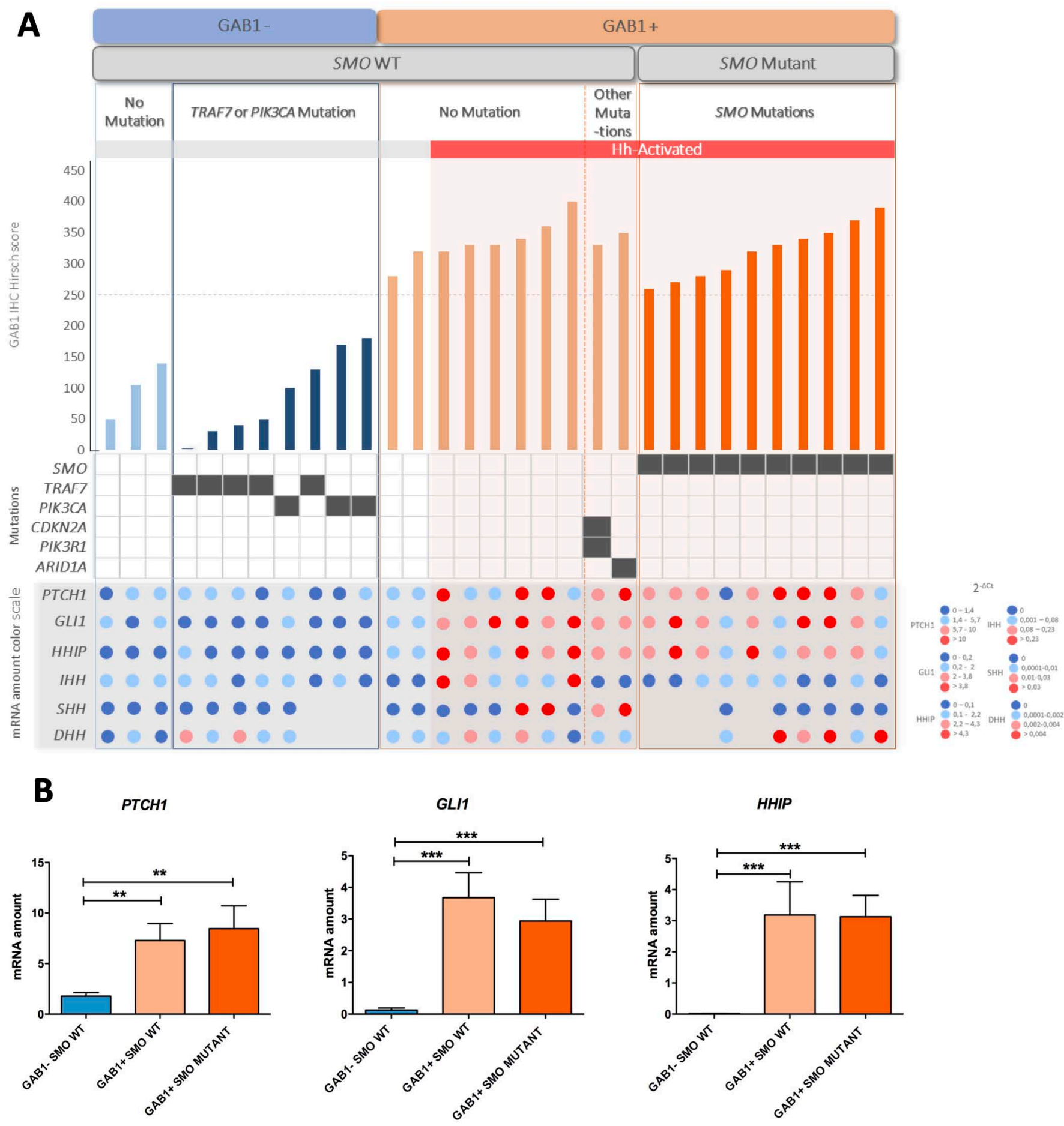


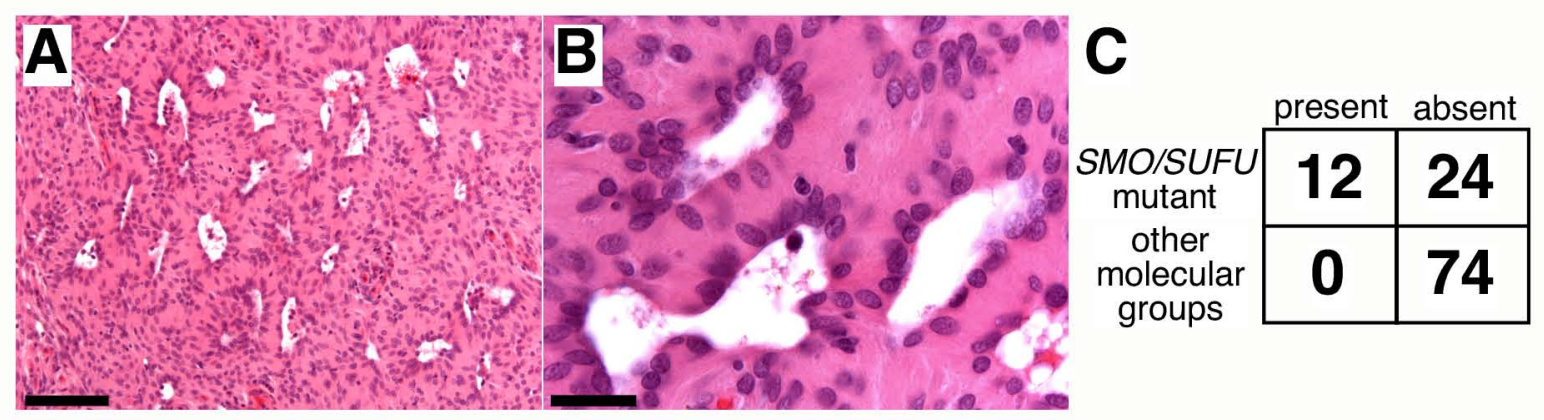


